Check for updates

Cite this: RSC Adv., 2020, 10, 21147

\title{
Study of the thermal decomposition mechanism of FOX-7 by molecular dynamics simulation and online photoionization mass spectrometry $\dagger$
}

\author{
Liping Jiang, (D) ${ }^{a}$ Xiaolong Fu, ${ }^{\text {a }}$ Zhongyue Zhou, ${ }^{\text {b }}$ Chongmin Zhang, (D) a Jizhen Li, ${ }^{a}$

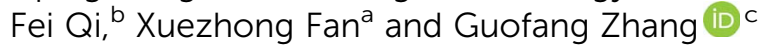

\begin{abstract}
The thermal decomposition mechanism of energetic materials is important for analyzing the combustion mechanisms of propellants and evaluating the safety of propellants during transport and storage. 1,1Diamino-2,2-dinitroethylene (FOX-7) is an important insensitive energetic material that can be used as an oxidizer in propellants. However, the initial decomposition mechanism of FOX-7 is not clear to date. The ReaxFF molecular dynamics method is widely used in the investigation of the thermal decomposition mechanisms of energetic materials. Meanwhile, the combination of thermogravimetry with online photoionization time-of-flight mass spectrometry (TG-PI-TOF-MS) and online single-photon ionization time-of-flight mass spectrometry (SPI-TOF-MS) can reveal the decomposition products, which may be integrated with the results of the simulation. In this study, the primary thermal decomposition mechanism of 1,1-diamino-2,2-dinitroethylene (FOX-7) was studied by the ReaxFF molecular dynamics simulations and online photoionization mass spectrometry. The results of the molecular dynamics simulations showed that the primary decomposition step of FOX-7 is C $-\mathrm{NO}_{2}$ cleavage; after this, $\mathrm{C}=\mathrm{O}$ formation occurs via a three-membered ring transition state, followed by $\mathrm{NO}$ elimination. The remaining structure loses $\mathrm{NH}_{2}$ and $\mathrm{H}$, resulting in the formation of the $\mathrm{NHC}=\mathrm{C}=\mathrm{O}$ structure, which finally breaks down into $\mathrm{HNC}$ and $\mathrm{CO}$. $\mathrm{NH}_{2}$ reacts with an $\mathrm{H}$ atom to produce $\mathrm{NH}_{3}$. A reversible intramolecular hydrogen transfer was also observed at $2500 \mathrm{~K}$; however, it failed to dominate the decomposition reaction. During the decomposition of FOX-7, the major products are $\mathrm{N}_{2}, \mathrm{NH}_{3}, \mathrm{CO}_{2}$, and $\mathrm{H}_{2} \mathrm{~N}_{2}$ and the minor products are $\mathrm{H}_{2} \mathrm{O}, \mathrm{HN}_{2}$, and $\mathrm{H}_{2}$. The TG-PI-TOF-MS spectrum shows three signals, i.e., $\mathrm{m} / \mathrm{z}=18,28$, and 30 , which can be assigned to $\mathrm{H}_{2} \mathrm{O}, \mathrm{CO}$, and $\mathrm{NO}$, respectively. Moreover, four signals at $\mathrm{m} / \mathrm{z}=72.72,55.81,45.79$, and 29.88 corresponding to the products $\left(\mathrm{NH}_{2}\right)_{2} \mathrm{C}=\mathrm{C}=\mathrm{O}$, $\left(\mathrm{NH}_{2}\right) \mathrm{C}=\mathrm{C}=\mathrm{O}, \mathrm{NO}_{2}$, and $\mathrm{NO}$ have been obtained in the SPI-TOF-MS spectrum. The experimental data obtained via online photoionization mass spectrometry further validated the results of the molecular dynamics simulations.
\end{abstract}

rsc.li/rsc-advances

Received 17th April 2020 Accepted 15th May 2020

DOI: $10.1039 / \mathrm{d} 0 \mathrm{ra0} 3443 \mathrm{f}$

\section{Introduction}

With the development of high-value weapon systems such as aircraft carriers, capital ships, strategic systems, and helicopters, new requirements have been placed on solid propellants, especially for improving their energy characteristics. The combustion and explosion of energetic materials during their transport and storage may lead to personal injury and property

${ }^{a} X i^{\prime} a n$ Modern Chemistry Research Institute, Xi'an, 710065, PR China. E-mail: fuxiaolong204@163.com

${ }^{b}$ Key Laboratory for Power Machinery and Engineering of Ministry of Education (MOE), Shanghai Jiao Tong University, Shanghai, 200240, PR China.E-mail: zhongyue.zhou@ sjtu.edu.cn.

${ }^{c}$ Key Laboratory of Applied Surface and Colloid Chemistry, MOE, School of Chemistry and Chemical Engineering, Shaanxi Normal University, Xi'an 710062, PR China

$\dagger$ Electronic supplementary information (ESI) available. See DOI: 10.1039/d0ra03443f damage. Therefore, the exploration of insensitive energetic materials for weapons is essential to improve the performance of weapons. To date, the well-known insensitive compounds mainly include 2,4-dinitroanisole (DNAN), 3-nitro-1,2,4-triazol5-one (NTO), nitroguanidine (NQ), ${ }^{1}$ 1,1-diamino-2,2dinitroethylene (FOX-7), and $N$-guanylurea-dinitramide (FOX12). ${ }^{2}$ As one of the representative insensitive compounds, FOX-7 was first synthesized in 1998 and subsequently, its crystal structure was determined. ${ }^{3-5}$ Due to its low sensitivity, ${ }^{6}$ high explosive performance, ${ }^{7}$ and excellent compatibility, ${ }^{8}$ FOX-7 is expected to be one of the promising insensitive energetic materials and may partially substitute conventional high-energy explosives in propellants. ${ }^{9}$

By studying the thermal decomposition behavior of energetic compounds, their possible performance changes during use and storage can be predicted. The thermal decomposition behavior of FOX-7 has attracted wide attention. Gindulyté et al. ${ }^{10}$ 
calculated the energy barrier of the possible primary step of nitro-to-nitrite rearrangement of FOX-7 via two methods: $59.1 \mathrm{kcal} \mathrm{mol}^{-1}$ via B3LYP and $59.7 \mathrm{kcal} \mathrm{mol}^{-1}$ via B3P86. The nitro-to-nitrite rearrangement was regarded as the most likely initial step. Kimmel ${ }^{11}$ used density functional theory (DFT) to investigate the electronic structure and dissociation pathways of FOX-7 in the gas phase. They found two competing initial decomposition mechanisms: $\mathrm{C}-\mathrm{NO}_{2}$ bond breakage and $\mathrm{C}-\mathrm{NO}_{2}$ to CONO isomerization. Zheng et al. ${ }^{12}$ simulated the thermolysis behavior of FOX-7 via the first-principles molecular dynamics approach. The results showed that $\mathrm{N}_{2}$ and $\mathrm{H}_{2} \mathrm{O}$ were the dominant products of thermal decomposition, and $\mathrm{NO}_{2}{ }^{+}$, $\mathrm{OH}^{-}$, and $\mathrm{NO}^{+}$served as intermediate products. Taylor et al. ${ }^{13}$ adopted a highly accurate SAPT(DFT) approach to develop a potential energy function for the 1,1-diamino-2,2dinitroethylene (FOX-7) energetic crystal. The intermolecular potential results in a crystal structure, and the thermal/pressure responses are in very good agreement with the experimental results. Based on the experimental results of nanosecond- and energy-resolved spectroscopy and CASSCF calculations, Yuan et $a{ }^{14}{ }^{14}$ concluded that the first step of FOX-7 ground-state decomposition is nitro-nitrite isomerization. Although a HONO product was energetically feasible, it was not the main initial decomposition product. Kiselev and Gritsan ${ }^{\mathbf{1 5}}$ revealed the primary reactions of FOX-7 in the gas phase by $\operatorname{CCSD}(\mathrm{T})-\mathrm{F} 12 /$ aVTZ calculations. Moreover, two unexpected initial reactions (enamino-imino isomerization and intramolecular cyclization) were found, and their activation energies were 48.4 and $28.8 \mathrm{kcal} \mathrm{mol}{ }^{-1}$, respectively. Liu et al. ${ }^{16}$ conducted $a b$ initio molecular dynamics simulations to study the decomposition reactions of solid FOX-7. The calculations revealed that the C$\mathrm{NO}_{2}$ bond fission is the most general route. Moreover, the interand intramolecular $\mathrm{H}$ transfers are possible. The major products were found to be $\mathrm{H}_{2} \mathrm{O}, \mathrm{CO}_{2}$, and $\mathrm{N}_{2}$. Booth and Butler ${ }^{17}$ explored the primary and subsequent steps by theoretical calculations at the G4//B3LYP/6-311++g(3df,2p) level. The results showed that the intramolecular $\mathrm{H}$ transfer from $\mathrm{NH}_{2}$ to $\mathrm{C} 2$ has the lowest energy barrier in isolated FOX-7 molecules. Jiang and co-workers ${ }^{\mathbf{1 8}}$ studied the early reactions of FOX-7 via self-consistent charge DFT tight-binding molecular dynamics simulations. The simulations suggested that the $\mathrm{C}-\mathrm{NO}_{2}$ rupture is indeed the dominant step that triggers the decomposition of FOX-7. The decomposition behavior of FOX-7 is related to the heating method. Zhu et al. ${ }^{19}$ performed DFTB-MD simulations to study the primary decomposition and combustion reaction mechanisms of isolated FOX-7 molecules. The results indicated that the initial step in the decomposition of isolated FOX-7 is $\mathrm{N}-\mathrm{O}$ bond breaking. After efforts for many years, numerous experiments have been conducted to investigate the decomposition mechanism of FOX-7 by theoretical calculation methods, which provide a basis for the in-depth understanding of the decomposition mechanism of FOX-7. However, the initial decomposition reaction mechanism is not clear to date, and there are very few studies whose results can be used to verify or integrated with the experimental results.

The ReaxFF molecular dynamics simulation not only can provide atomistic information but can also simulate the thermal decomposition mechanisms and shock sensitivity of energetic materials (EMs) including hexahydro-1,3,5-trinitro1,3,5-s-triazine (RDX), ${ }^{20-22}$ octahydro-1,3,5,7-tetranitro-1,3,5,7tetrazocine (HMX), ${ }^{23-25}$ triacetone triperoxide (TATP), ${ }^{26}$ pentaerythritol tetranitrate (PETN), ${ }^{27}$ trinitrotoluene $(\mathrm{TNT}),{ }^{28}$ and hexanitrohexaazaisowurtzitane (CL-20). ${ }^{\mathbf{2 9}, 30}$ The ReaxFF method was also applied to investigate the decomposition processes of energetic composite nanomaterials. ${ }^{31,32}$ The ReaxFF molecular dynamics simulations show significant advantages in studying the decomposition mechanisms of energetic compounds since using these simulations, the thermal decomposition processes of energetic compounds can be comprehensively investigated.

Recently, mass spectrometry combined with soft ionization technology has been proved to achieve the real-time and online analysis of coal and biomass pyrolysis, ${ }^{33,34}$ and it has high sensitivity and ultrahigh resolution and does not require sample preparation. Thermogravimetry (TG) coupled with online photoionization time-of-flight mass spectrometry (PITOF-MS) has been successfully used to evaluate the copyrolysis of kraft lignin (KL) and lignite (LI). ${ }^{35}$ Additionally, Wang's group has conducted the thermal and catalytic pyrolysis of polypropylene (PP) and $\mathrm{PP} / 50 \% \mathrm{HZSM}-5$ at various temperatures by an online single-photon ionization time-of-flight mass spectrometry (SPI-TOF-MS). ${ }^{36,37}$ Most of the usual energetic compounds have relatively simple structures, and it is expected that future studies related to the thermal decomposition of energetic compounds can be performed using on-line photoionization mass spectrometry techniques.

In this study, we focused on the investigation of the initial thermal decomposition mechanisms of FOX-7 by two methods: online photoionization mass spectrometry and ReaxFF molecular dynamics simulations. The evolution of product distribution and the pathway of the unimolecular thermolysis of FOX-7 were also discussed in detail. Meanwhile, we determined the pathways for the formation of the final products from the initial products and intermediate products. This work is helpful to obtain insights into the thermal decomposition mechanisms of FOX-7.

\section{Methods}

\subsection{TG-PI-TOF-MS}

The TG-PI-TOF-MS setup comprises a commercial TG analyzer (Discovery TGA, TA Instruments) and a homemade TOF mass spectrometer. A schematic of the TG analyzer combined with a photoionization time-of-flight mass spectrometer is exhibited in Fig. 1. The TG experiments were conducted using a thermogravimetric analyzer (Discovery TGA, TA Instruments), and the sample mass was about $10 \mathrm{mg}$. The homemade TOF mass spectrometer was applied to detect the product signals generated during the decomposition experiments. In order to eliminate the interference of nitrogen, we used an argon atmosphere. The temperature program was set as follows: the system was maintained at $50{ }^{\circ} \mathrm{C}$ for $10 \mathrm{~min}$, heated to $400{ }^{\circ} \mathrm{C}$ at the rate of $5{ }^{\circ} \mathrm{C} \mathrm{min}{ }^{-1}$, and then maintained at $400{ }^{\circ} \mathrm{C}$ for $1 \mathrm{~min}$. The flow rate of argon was kept at $50 \mathrm{~mL} \mathrm{~min}^{-1}$ during the experiment. As shown in Fig. 1, the PI-TOF mass spectrometer consists of a sampling interface, a photoionization chamber, a DC-only 


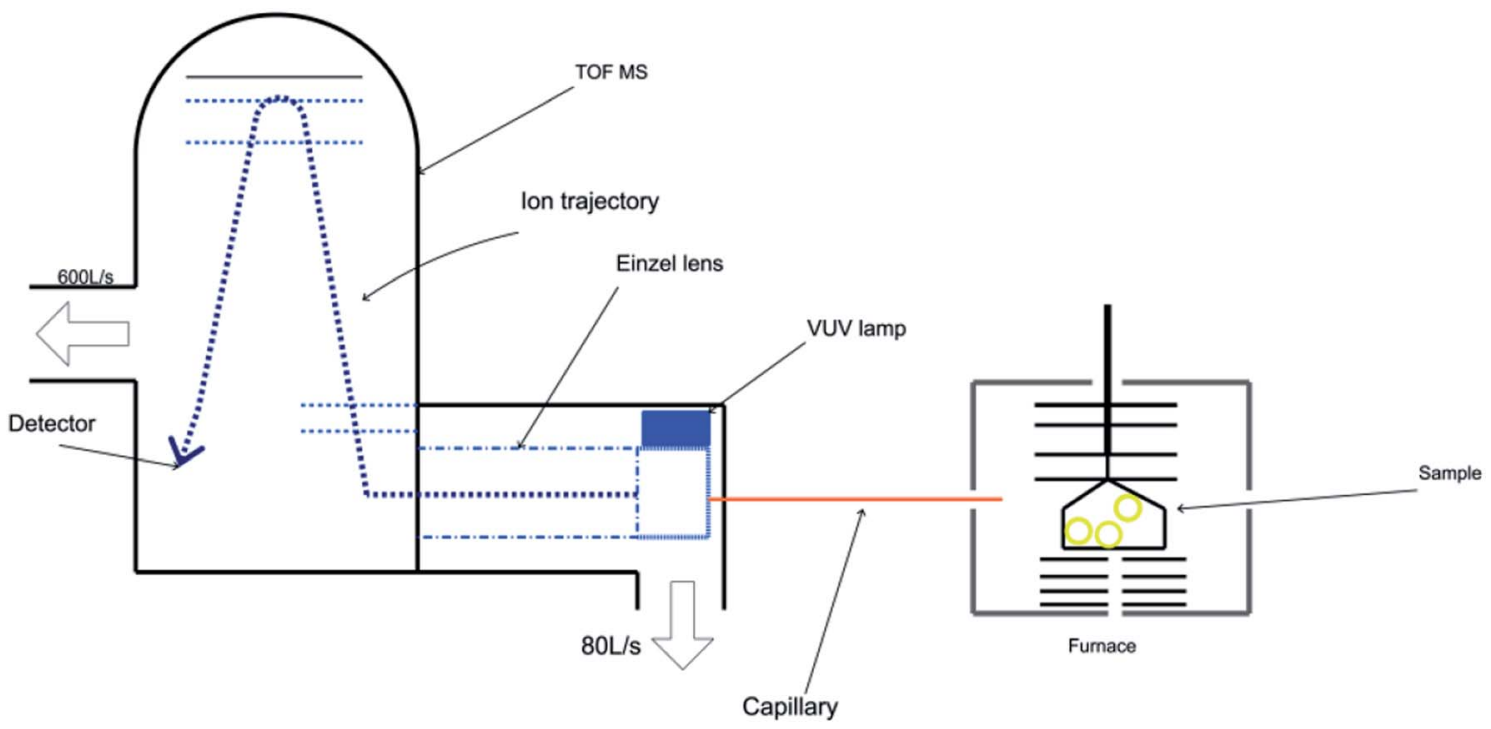

Fig. 1 Schematic of the TG analyzer combined with a photoionization time-of-flight mass spectrometer.

einzel lens, and a reflectron TOF mass analyzer with a mass resolution of approximately $3000(\mathrm{~m} / \Delta \mathrm{m})$. The evolved gases were sampled by a fused silica capillary with an inner diameter of $70 \mu \mathrm{m}$, which was then introduced into the photoionization chamber. The temperature of the capillary was kept at $200{ }^{\circ} \mathrm{C}$, and the pressure of the photoionization chamber was maintained at $8.5 \times 10^{-2} \mathrm{~Pa}$ by an $80 \mathrm{~L} \mathrm{~s}^{-1}$ molecular pump. The pressure of the TOF mass analyzer was kept at $5.0 \times 10^{-5}$ Pa by a $600 \mathrm{~L} \mathrm{~s}^{-1}$ molecular pump. The thermolysis products were ionized by $10.6 \mathrm{eV}$ photons emitted from a vacuum ultraviolet (VUV) lamp (Heraeus, Ltd.) and analyzed by the TOF mass analyzer. The data were obtained every $60 \mathrm{~s}$. Data processing was performed using the MATLAB software.

\subsection{SPI-TOF-MS}

The setup of SPI-TOF-MS is composed of a tubular furnace, heated transfer line, and homemade photoionization orthogonal acceleration TOF-MS. Fig. 2 shows a schematic of the SPITOF-MS system. The tubular temperature was controlled by a temperature controller (SKY Technology Development Co., Shenyang, China) and measured using a K-type thermocouple. Argon was used as the carrier gas $(200 \mathrm{sccm})$ to provide an inert atmosphere. Ethylene (Nanjing Special Gas Factory Co., Ltd.,

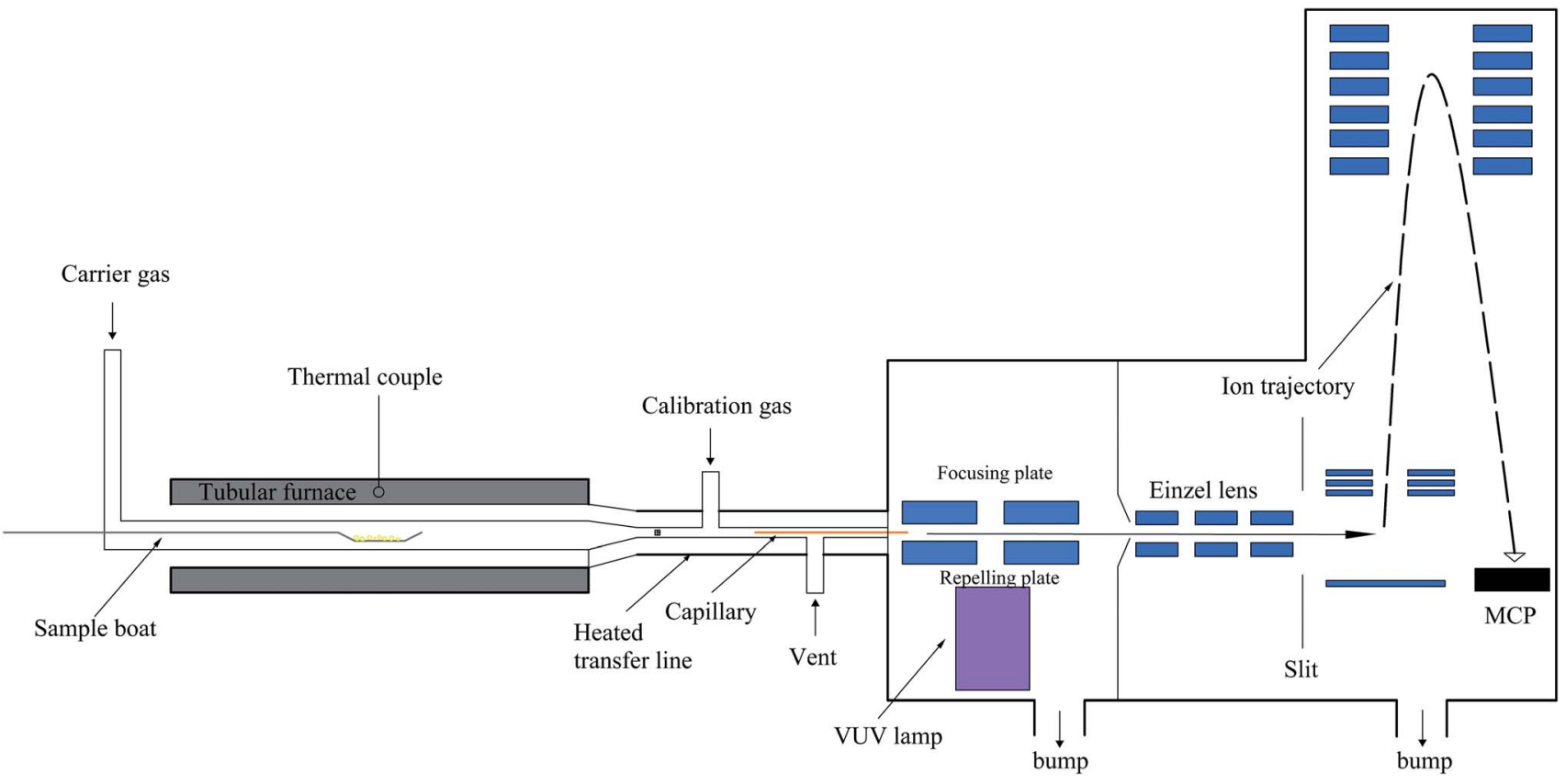

Fig. 2 Schematic of the SPI-TOF-MS system. 
Table 1 Comparison between the computational and experimental unit cell lattice parameters of FOX-7

\begin{tabular}{|c|c|c|c|c|c|c|c|c|}
\hline & Method & $a(\AA)$ & $b(\AA)$ & $c(\AA)$ & $\alpha$ (deg) & $\beta$ (deg) & $\gamma(\mathrm{deg})$ & Density $\left(\mathrm{g} \mathrm{cm}^{-3}\right)$ \\
\hline CCDC & X-ray & 6.941 & 6.569 & 11.315 & 90.00 & 90.55 & 90.00 & 1.914 \\
\hline This work & ReaxFF-lg & 6.922 & 6.554 & 11.281 & 90.00 & 90.55 & 90.00 & 1.92 \\
\hline
\end{tabular}
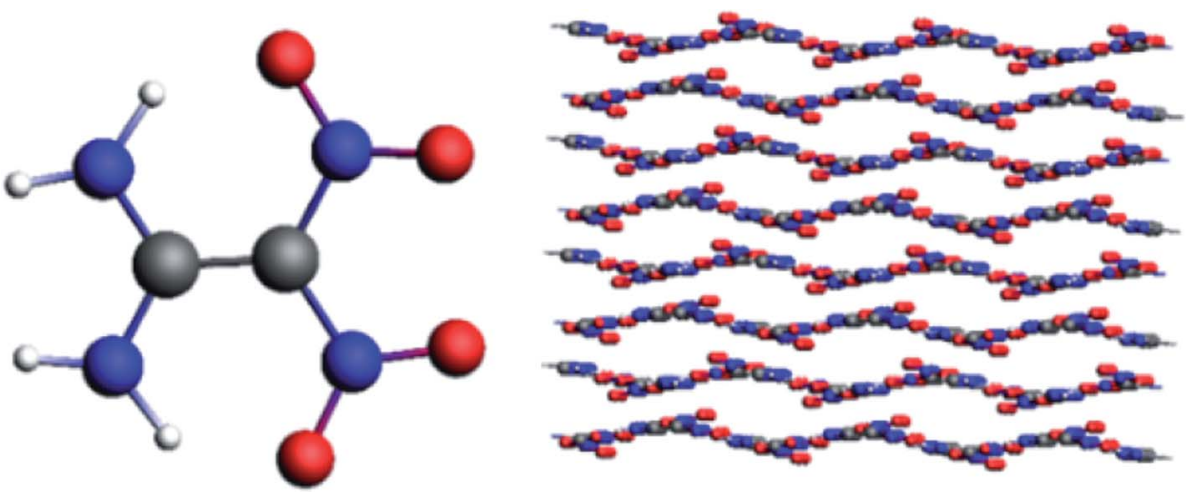

Fig. 3 Molecular structure and supercell of FOX-7.

China) was used for the calibration of the VUV light intensity. Since we wanted to investigate the entire decomposition process, a $10 \mathrm{mg}$ sample was placed on a sample boat and then introduced into the furnace. In the present study, the temperature was increased from $50{ }^{\circ} \mathrm{C}$ to $400{ }^{\circ} \mathrm{C}$ at the rate of $5{ }^{\circ} \mathrm{C} \min ^{-1}$. The pyrolysis products were passed through a glass fiber filter with a pore size of $1.2 \mu \mathrm{m}$ and then introduced into a deactivated fused-silica capillary for extracting partially gaseous products. The gaseous samples introduced into the middle region between the repelling and focusing electrodes were ionized by the crossed VUV light. Subsequently, the produced ions were introduced into the mass spectrometer chamber via a nickel skimmer (1 $\mathrm{mm}$ inner diameter, Beam Dynamics, Jacksonville, FL) and focused by a set of einzel lenses. The ions were then transmitted through a slit $(2 \mathrm{~mm} \times 10$ $\mathrm{mm}$ ) into the extract region and detected by a reflectron TOFMS. A VT120C preamplifier (EG\&G, ORTEC, Oak Ridge, TN) was used to amplify the ion signals, which were then recorded by the P7888 multiscaler (FAST Comtec, Oberhaching, Germany). The data was acquired every 60 seconds and processed by the MATLAB software.

\subsection{Simulation details}

The ReaxFF method is a molecular force field method based on the bond order; it is often used in molecular dynamics simulations, and its accuracy is similar to or better than that of PM3. The energy terms that constitute the total energy are the bond energy, over-coordination penalty energy, under-coordination correction energy, torsion angle energy, valence angle energy, lone-pair electron energy, coulomb interaction energies, and van der Waals interaction energy, as presented in eqn (1).

$$
\begin{aligned}
E_{\text {ReaxFF }}= & E_{\text {bond }}+E_{\text {over }}+E_{\text {under }}+E_{\text {tors }}+E_{\mathrm{val}}+E_{\mathrm{lp}} \\
& +E_{\text {coul }}+E_{\mathrm{vdW}}
\end{aligned}
$$

The total energy of the ReaxFF-lg force field and the longrange-correction terms were calculated using the low-gradient model, as presented by eqn (2) and (3), respectively.

$$
\begin{gathered}
E_{\text {ReaxFF-1g }}=E_{\mathrm{ReaxFF}}+E_{\mathrm{lg}} \\
E_{\mathrm{lg}}=-\sum_{i j, i<j}^{N} \frac{C_{\mathrm{lg}, i j}}{r_{i j}{ }^{6}+d R_{e i j}{ }^{6}}
\end{gathered}
$$

The crystal structure of FOX-7 was obtained from the Cambridge Data Centre (CCDC number: 130779). The unit cell contains four molecules. We first implemented geometry optimization via the ReaxFF-lg method and obtained the lattice parameters; then, we compared the obtained results with the $\mathrm{X}$ ray experimental data, as presented in Table 1. The optimized unit cell parameters are very close to the experimental values; this indicates that the ReaxFF-lg force field method can be a reliable method to describe the crystal structure of FOX-7.

The $4 \times 4 \times 3$ supercell was established by enlarging the unit cell along the $a, b$, and $c$ axes, which contains 48 unit cells, 192 FOX-7 molecules, and 2688 atoms, as shown in Fig. 3. The reactive molecular dynamics simulations were performed using the ADF software package with the ReaxFF-lg force field. The 50 ps microcanonical (NVE) simulation was carried out, followed by the 50 ps isothermal-isochoric (NVT) and 200 ps isothermalisobaric (NPT) MD simulations with a time step of 0.25 fs to relax the structure at $298 \mathrm{~K}$ under $0.1 \mathrm{MPa}$. The damping constants of the Nose-Hoover chain thermostat and NHCP anisotropic barostat were $100 \mathrm{fs}$ and $500 \mathrm{fs}$, respectively. The density obtained by the NPT simulation is 1.92 . After the $200 \mathrm{ps}$ NPT simulation, 200 ps NVT Nose-Hoover chain simulations with a time step of 0.25 fs were conducted at 2000, 2500, 3000, 3500 , and $4000 \mathrm{~K}$. We estimated chemical bond formation when the bond order was equal to or greater than 0.3 . 

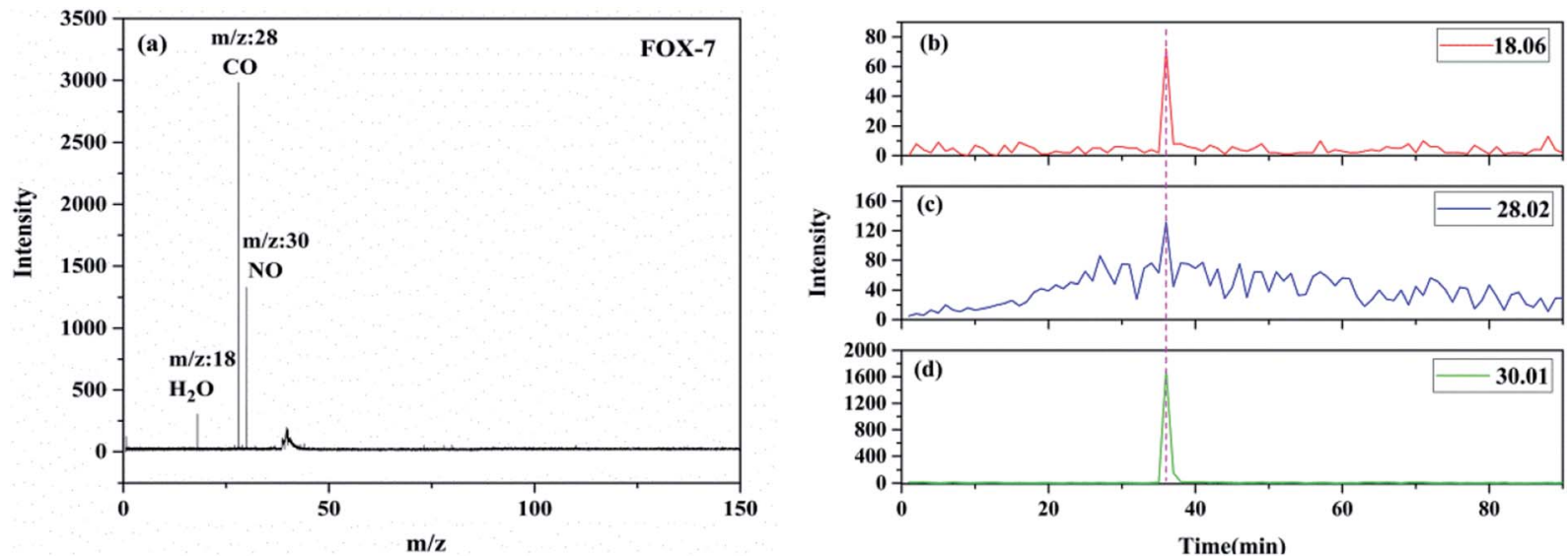

Fig. 4 The TG-PI-TOF-MS spectrum of FOX-7 (a); evolutions of the thermolytic products of FOX-7 during the decomposition process: (b) $m / z=$ 18.06, (c) $m / z=28.02$, and (d) $m / z=30.01$.
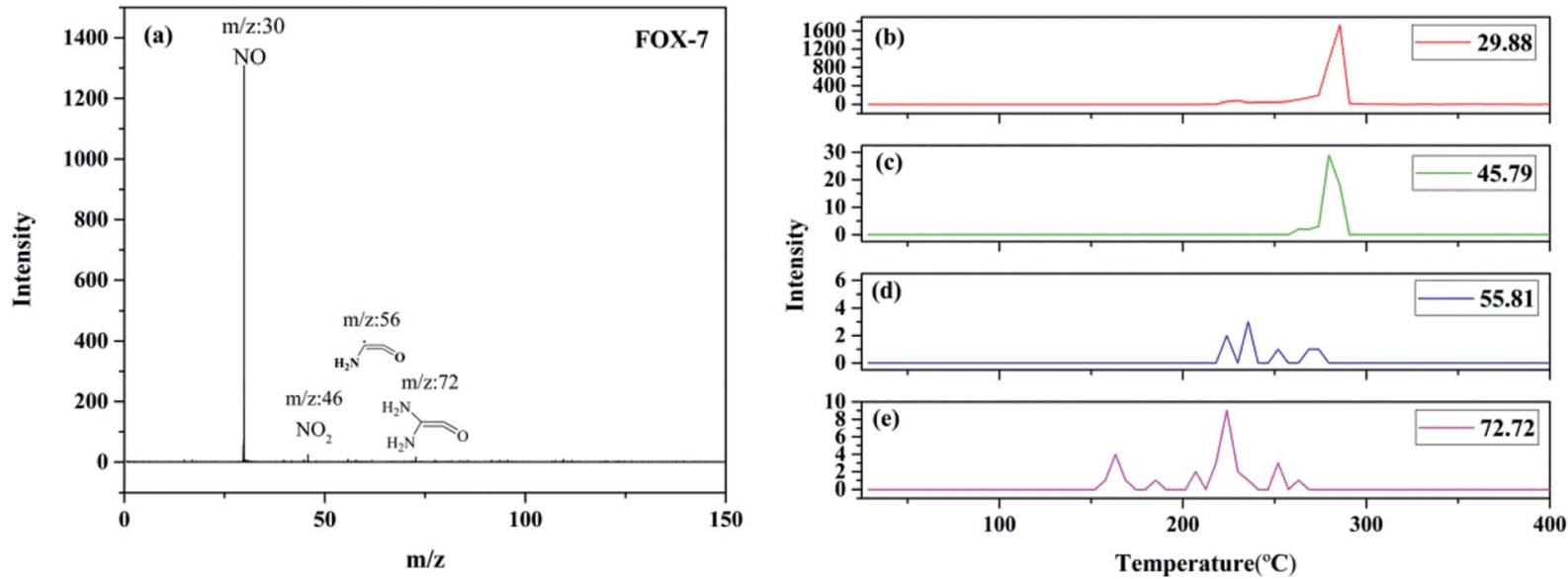

Fig. 5 The SPI-TOF-MS spectrum of FOX-7 (a); evolutions of the thermolysis products of FOX-7 during the decomposition process: (b) $m / z=$ 29.88 , (c) $m / z=45.79$, (d) $m / z=55.81$, and (e) $m / z=72.72$.

\section{Results and discussion}

\subsection{TG-PI-TOF-MS and TOF-MS experiments}

Nearly all the mass peaks obtained upon the near-threshold "soft" photoionization could be assigned to the parent ions with few or no fragments. The TG-PI-TOF-MS and SPI-TOF-MS techniques were used to detect the pyrolysis products and reaction intermediates. The reaction network could be inferred from these products. The TG-PI-TOF-MS experimental results are shown in Fig. 4. The TG-PI-TOF-MS spectrum shows the signals of three products at $m / z=18, m / z=28$, and $m / z=30$. The signals at $m / z=18$ and $m / z=30$ were assigned to $\mathrm{H}_{2} \mathrm{O}$ and NO, respectively. The mass-to-charge ratio of 28 may be attributed to CO. In the experiment, FOX-7 was heated starting from $50{ }^{\circ} \mathrm{C}$ at the heating rate of $5{ }^{\circ} \mathrm{C}$ per minute, a temperature of about $230{ }^{\circ} \mathrm{C}$ was reached at the thirty-sixth minute, and these three products were generated in a significant amount by the thermal decomposition of FOX-7. The peak of NO is obviously stronger than those of the other two products. All the minor

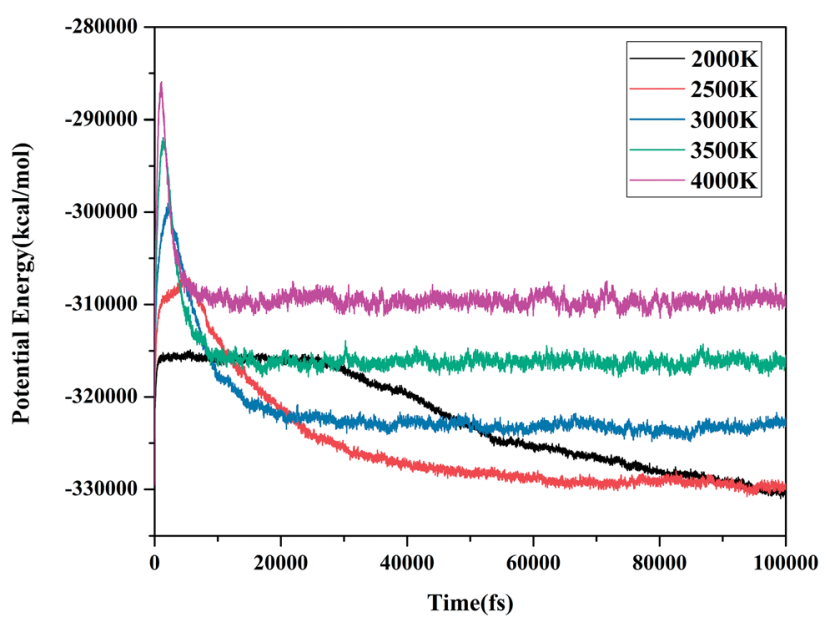

Fig. 6 Evolution of the potential energy with time at various MD simulation temperatures. 

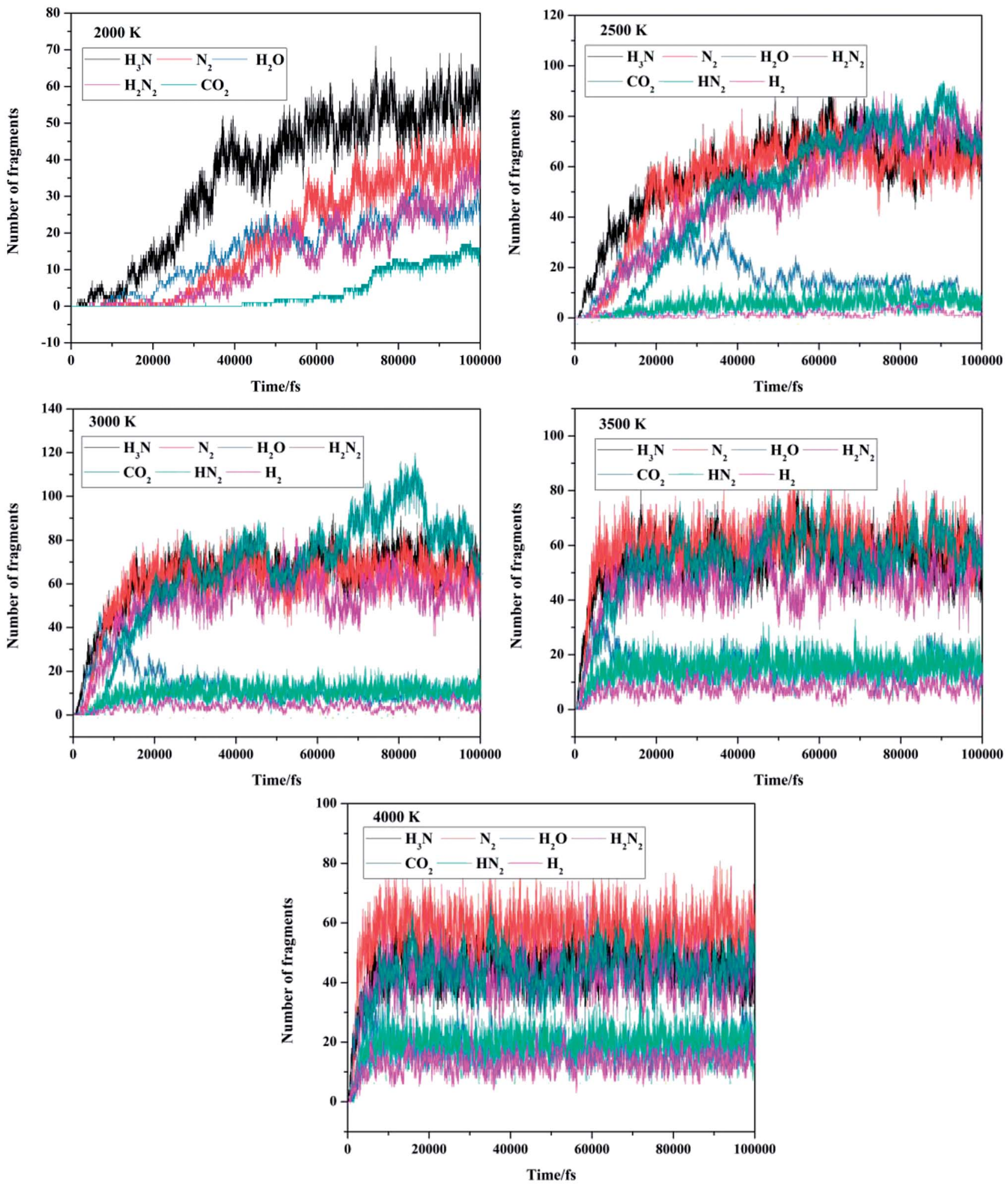

Fig. 7 Evolution of the major products of FOX-7 decomposition at various MD simulation temperatures.

products were mainly produced in the low-temperature exothermic stage of FOX-7 decomposition.

Fig. 5 shows the SPI-TOF-MS experimental results of FOX-7. As can be observed from the results, four peaks at $m / z=29.88,45.79$, 55.81 , and 72.72 were detected. The peaks at $m / z=29.88$ and
45.79 were readily assigned to $\mathrm{NO}$ and $\mathrm{NO}_{2}$, respectively. The mass-to-charge ratios of 55.81 and 72.72 may be ascribed to $\left(\mathrm{NH}_{2}\right)$ $\mathrm{C}=\mathrm{C}=\mathrm{O}$ and $\left(\mathrm{NH}_{2}\right)_{2} \mathrm{C}=\mathrm{C}=\mathrm{O}$, respectively. The maximum intensity peaks corresponding to nitrogen dioxide and nitric oxide were obtained at 279.87 and $285.51{ }^{\circ} \mathrm{C}$, respectively, which 

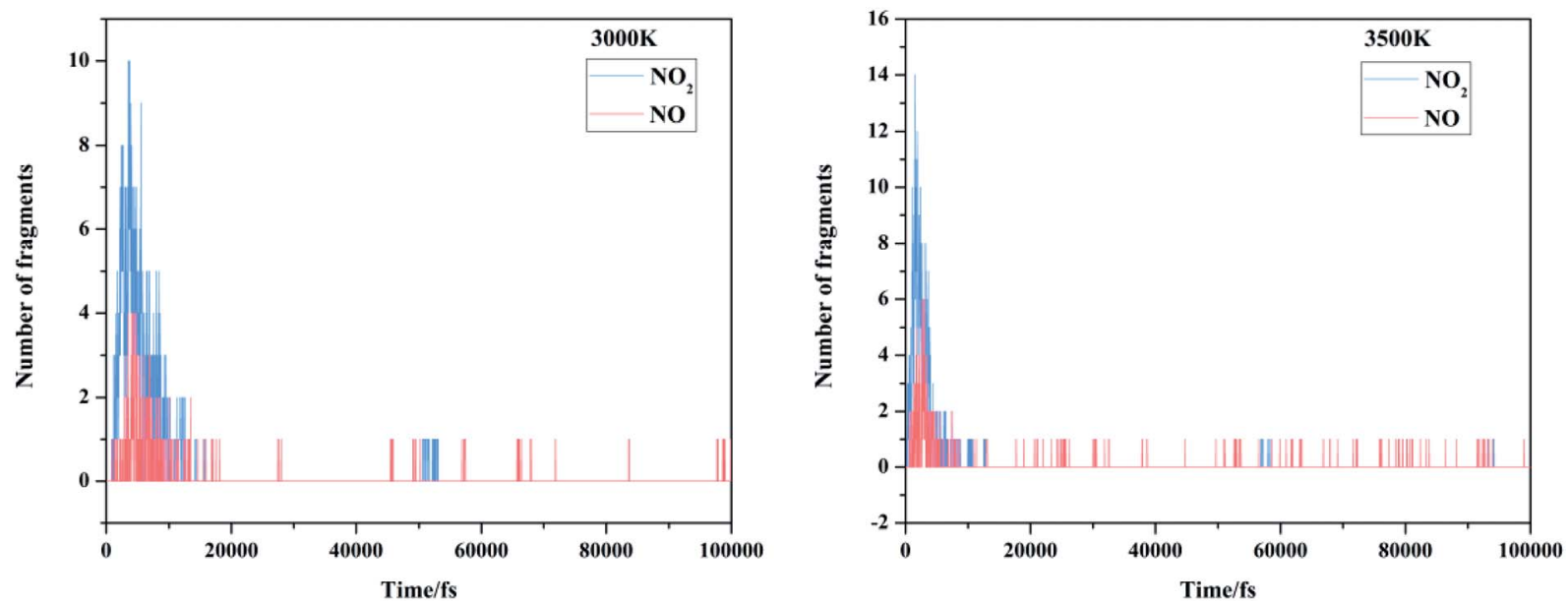

Fig. 8 The evolution of the initial/intermediate products $\mathrm{NO}_{2}$ and $\mathrm{NO}$ at $3000 \mathrm{~K}$ and $3500 \mathrm{~K}$.

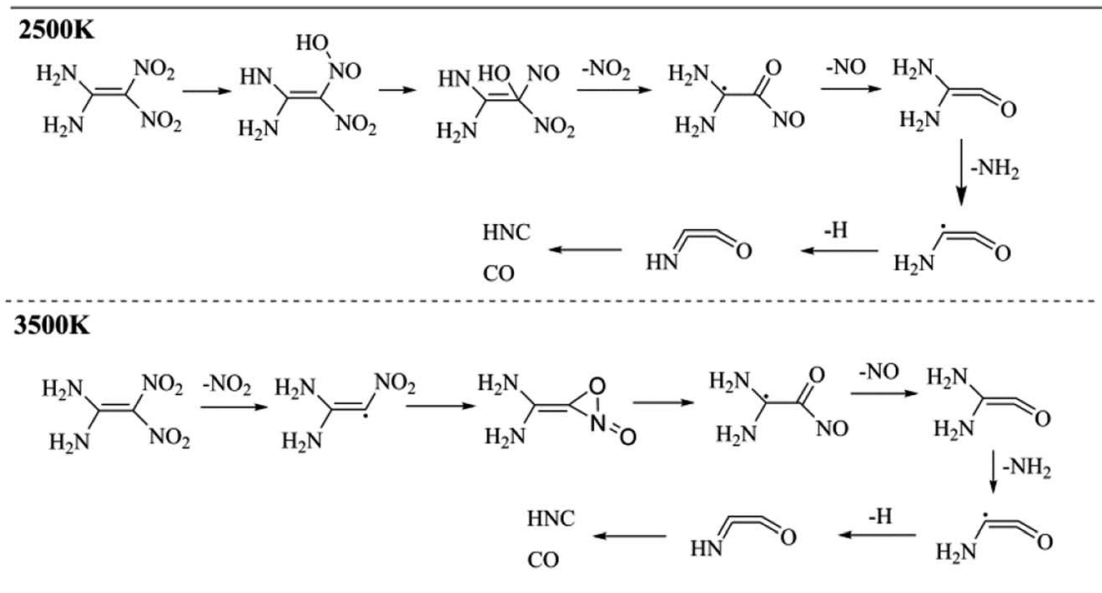

Fig. 9 Primary decomposition reactions of FOX-7.

demonstrate that nitrogen dioxide is produced before nitric oxide. Therefore, the primary decomposition reaction of FOX-7 is initiated by the $\mathrm{C}-\mathrm{NO}_{2}$ fission. The earliest appeared fragment was $\left(\mathrm{NH}_{2}\right)_{2} \mathrm{C}=\mathrm{C}=\mathrm{O}$, and its maximum intensity peak appeared at $223{ }^{\circ} \mathrm{C}$; thus, this fragment might have originated from the $\mathrm{C}-\mathrm{NO}_{2}$ cleavage, followed by the loss of NO. The mass-to-charge ratio of 55.81 with the maximum intensity peak at $235{ }^{\circ} \mathrm{C}$ belonged to $\left(\mathrm{NH}_{2}\right) \mathrm{C}=\mathrm{C}=\mathrm{O}$, which was generated by the removal of a $\mathrm{NH}_{2}$ species from $\left(\mathrm{NH}_{2}\right)_{2} \mathrm{C}=\mathrm{C}=\mathrm{O}$.

\subsection{Evolution of energy release and product distribution}

Molecular potential energy (PE) is closely related to molecular interactions and the relative positions of molecules. ${ }^{38}$ It can intuitively indicate the change in the potential energy with time. Meanwhile, the degree of reaction can also be determined. Fig. 6 shows the evolution of PE with time at various molecular dynamics simulations temperatures. When the PE approached a stable value, we considered that the decomposition reaction was completed. Based on these judgment conditions, it seems that the reaction did not reach equilibrium at $2000 \mathrm{~K}$ and $2500 \mathrm{~K}$ during the entire simulations. After $20 \mathrm{ps}$, the potential energy became stable at 3000,3500 , and $4000 \mathrm{~K}$. The PE curves showed similar trends at different temperatures. The decomposition process undergoes three stages: increasing to a maximum, decreasing, and finally balancing, simultaneously, the maximum and equilibrium values of the PE increased with the increasing temperature.

The distribution of the products generated by FOX-7 decomposition can also be obtained through the ReaxFF molecular dynamics simulation. The evolution of the major products of FOX-7 decomposition is shown in Fig. 7. Partial products were observed at 2000 and $2500 \mathrm{~K}$; this indicates that the decomposition reaction may not be completely accomplished. The product evolution curves at 3000, 3500, and $4000 \mathrm{~K}$ are similar. All the final products start to appear at $2500 \mathrm{~K}$. In Fig. 7, we can observe that after thermal decomposition, $\mathrm{N}_{2}$, $\mathrm{NH}_{3}, \mathrm{CO}_{2}$, and $\mathrm{H}_{2} \mathrm{~N}_{2}$ are the dominant products and $\mathrm{H}_{2} \mathrm{O}, \mathrm{HN}_{2}$, and $\mathrm{H}_{2}$ are the minor products. The amount of $\mathrm{H}_{2} \mathrm{O}$ molecules first increases and then gradually decreases with time; this represents the formation and consumption of $\mathrm{H}_{2} \mathrm{O}$ molecules. The populations of other products increase in the initial stages 


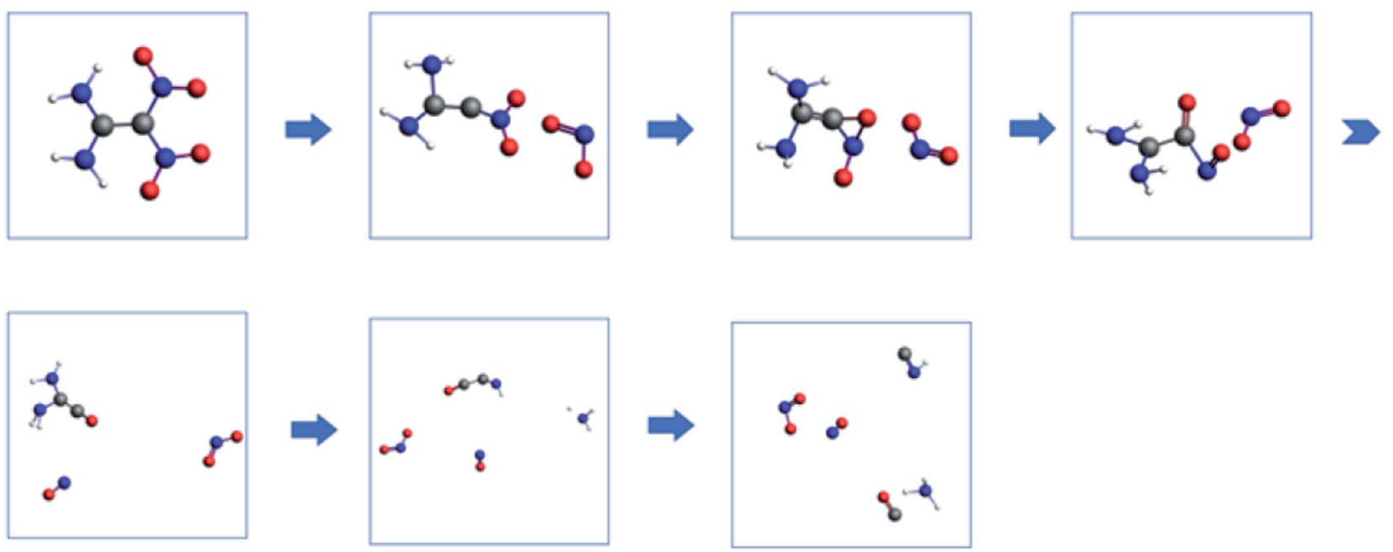

Fig. 10 Proposed decomposition pathway of FOX-7 (the $\mathrm{C}, \mathrm{H}, \mathrm{O}$, and $\mathrm{N}$ atoms are represented by gray, white, red and blue, respectively).

Table 2 Formation mechanisms of the final products

\begin{tabular}{|c|c|}
\hline General molecular species & The main chemical reactions \\
\hline $\mathrm{CO}_{2}$ & $\begin{array}{l}\text { (1) } \mathrm{CO}+\mathrm{CO} \rightarrow \mathrm{CO}_{2}+\mathrm{O} \\
\text { (2) } \mathrm{CO}+\mathrm{CO}_{2} \rightarrow \mathrm{CO}_{2}+\mathrm{CO} \\
\text { (3) } \mathrm{NO}_{2}+\mathrm{CO} \rightarrow \mathrm{CO}_{2}+\mathrm{NO} \\
\text { (4) } \mathrm{NO}+\mathrm{CO} \rightarrow \mathrm{CO}_{2}+\mathrm{N}\end{array}$ \\
\hline $\mathrm{H}_{2} \mathrm{O}$ & 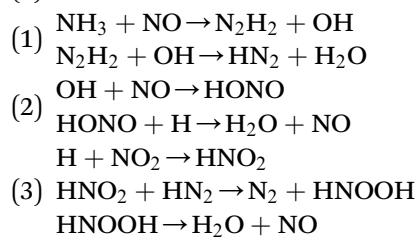 \\
\hline $\mathrm{N}_{2}$ & $\begin{array}{l}\text { (1) } \mathrm{HN}_{2} \rightarrow \mathrm{H}+\mathrm{N}_{2} \\
\text { (2) } \mathrm{H}_{2} \mathrm{~N}_{2} \rightarrow \mathrm{H}_{2}+\mathrm{N}_{2}\end{array}$ \\
\hline $\mathrm{NH}_{3}$ & (1) $\mathrm{NH}_{2}+\mathrm{H} \rightarrow \mathrm{NH}_{3}$ \\
\hline $\mathrm{N}_{2} \mathrm{H}_{2}$ & $\begin{array}{l}\text { (1) } \mathrm{H}_{2} \mathrm{~N}_{2}+\mathrm{HN}_{2} \rightarrow \mathrm{HN}_{2}+\mathrm{H}_{2} \mathrm{~N}_{2} \\
\text { (2) } 2 \mathrm{NH} \rightarrow \mathrm{H}_{2} \mathrm{~N}_{2} \\
\text { (3) } \mathrm{H}_{2}+\mathrm{N} 2 \rightarrow \mathrm{H}_{2} \mathrm{~N}_{2}\end{array}$ \\
\hline $\mathrm{H}_{2}$ & $\begin{array}{l}\text { (1) } \mathrm{NH}_{3} \rightarrow \mathrm{H}_{2}+\mathrm{NH} \\
\mathrm{NH}_{2}+\mathrm{H} \rightarrow \mathrm{NH}_{3} \\
\text { (2) } \mathrm{NH}_{3}+\mathrm{H} \rightarrow \mathrm{NH}_{3} \\
\mathrm{NH}_{4} \rightarrow \mathrm{H}_{2}+\mathrm{NH}_{2} \\
\text { (3) } \mathrm{HN}_{2}+\mathrm{HNC} \rightarrow \mathrm{H}_{2} \mathrm{~N}_{2}+\mathrm{CN} \\
\text { (4) } \mathrm{H}_{3} \mathrm{~N}_{2} \rightarrow \mathrm{H}_{2}+\mathrm{HN}_{2} \\
\text { (5) } \mathrm{H}_{2} \mathrm{~N}_{2} \rightarrow \mathrm{H}_{2}+\mathrm{N}_{2}\end{array}$ \\
\hline $\mathrm{HN}_{2}$ & $\begin{array}{l}\text { (1) } \mathrm{N}_{2} \mathrm{H}_{2} \rightarrow \mathrm{HN}_{2}+\mathrm{H} \\
\text { (2) } \mathrm{N}_{2}+\mathrm{H} \rightarrow \mathrm{HN}_{2} \\
\text { (3) } \mathrm{H}+\mathrm{NO}_{2} \rightarrow \mathrm{HNO}_{2} \\
\mathrm{HNO}_{2}+\mathrm{N}_{2} \rightarrow \mathrm{HN}_{2}+\mathrm{NO}_{2} \\
\text { (4) } \mathrm{H}_{2} \mathrm{~N}_{2}+\mathrm{OH} \rightarrow \mathrm{HN}_{2}+\mathrm{H}_{2} \mathrm{O} \\
\text { (5) } \mathrm{NH}_{3}+\mathrm{N}_{2} \rightarrow \mathrm{NH}_{2}+\mathrm{HN}_{2}\end{array}$ \\
\hline
\end{tabular}

and then become stable. The cases of the initial/intermediate products $\left(\mathrm{NO}_{2}\right.$ and $\left.\mathrm{NO}\right)$ have been discussed in the Section 3.3.

\subsection{Initial thermal decomposition reactions}

There are mainly three popular views on the initial decomposition step of FOX-7: nitro-to-nitrite rearrangement, direct cleavage of the nitro group on the carbon atom, and intermolecular or intramolecular hydrogen transfer. We first focused on the emergence order of nitro and nitric oxide during the entire MD simulations. The evolution of the initial/intermediate products $\mathrm{NO}_{2}$ and $\mathrm{NO}$ is exhibited in Fig. 8. It can be clearly observed from our dynamic calculations that nitrogen dioxide appeared earlier than nitric oxide; this demonstrates that the primary reaction of FOX-7 decomposition is $\mathrm{C}-\mathrm{NO}_{2}$ cleavage.

The molecular dynamics simulations can generate a series of trajectory images, from which the decomposition pathway can be determined. Therefore, the unimolecular decomposition reactions of FOX-7 via the 37.5 ps NVT Berendsen simulations with a time step of $0.25 \mathrm{fs}$ at $2500 \mathrm{~K}$ and bimolecular reactions via the 100 ps NVT Berendsen simulations with the same time step at $3500 \mathrm{~K}$ were investigated. Fig. 9 displays two schematics of the decomposition pathways at $2500 \mathrm{~K}$ and $3500 \mathrm{~K}$. The corresponding images are presented in Fig. S1 $\dagger$ and 10. An obvious conclusion is that the initial decomposition step of FOX-7 is $\mathrm{C}-\mathrm{NO}_{2}$ cleavage. The intramolecular $\mathrm{H}$ transfer occurs at $2500 \mathrm{~K}$, and then, the structure is converted to $\left(\mathrm{NH}_{2}\right)_{2} \mathrm{C}=\mathrm{C}=$ $\mathrm{O}$ with the loss of nitric oxide. After the cleavage of $\mathrm{C}-\mathrm{NO}_{2}$, the remaining structure passes through a three-membered ring transition state to form a $\mathrm{C}=\mathrm{O}$ bond. The third step is $\mathrm{C}-\mathrm{NO}$ cleavage followed by the elimination of $\mathrm{NH}_{2}$ and $\mathrm{H}$. The $\mathrm{HNC}=$ $\mathrm{C}=\mathrm{O}$ structure decomposes into $\mathrm{HNC}$ and $\mathrm{CO}$.

\subsection{Proposed decomposition pathway}

Based on the mass spectrometry results, a decomposition strategy was proposed. The decomposition reaction of FOX-7 is initiated by the $\mathrm{C}-\mathrm{NO}_{2}$ fission, and then, the remaining structure passes through a three-membered ring transition state to form the $\mathrm{C}=\mathrm{O}$ bond followed by the cleavage of $\mathrm{C}-\mathrm{NO}$ and loss of $\mathrm{NH}_{2}$ and $\mathrm{H}$; this results in formation of the $\mathrm{NHC}=\mathrm{C}=\mathrm{O}$ structure, which finally breaks down into $\mathrm{HNC}$ and CO. $\mathrm{NH}_{2}$ can react with the $\mathrm{H}$ atom to produce $\mathrm{NH}_{3}$; this results in an increase in the number of $\mathrm{NH}_{3}$ molecules. The corresponding decomposition pathway is shown in Fig. 10.

\subsection{Formation mechanisms of the final products}

In order to investigate the formation mechanism of the final products, the 100 ps NVT Berendsen simulations with a time 

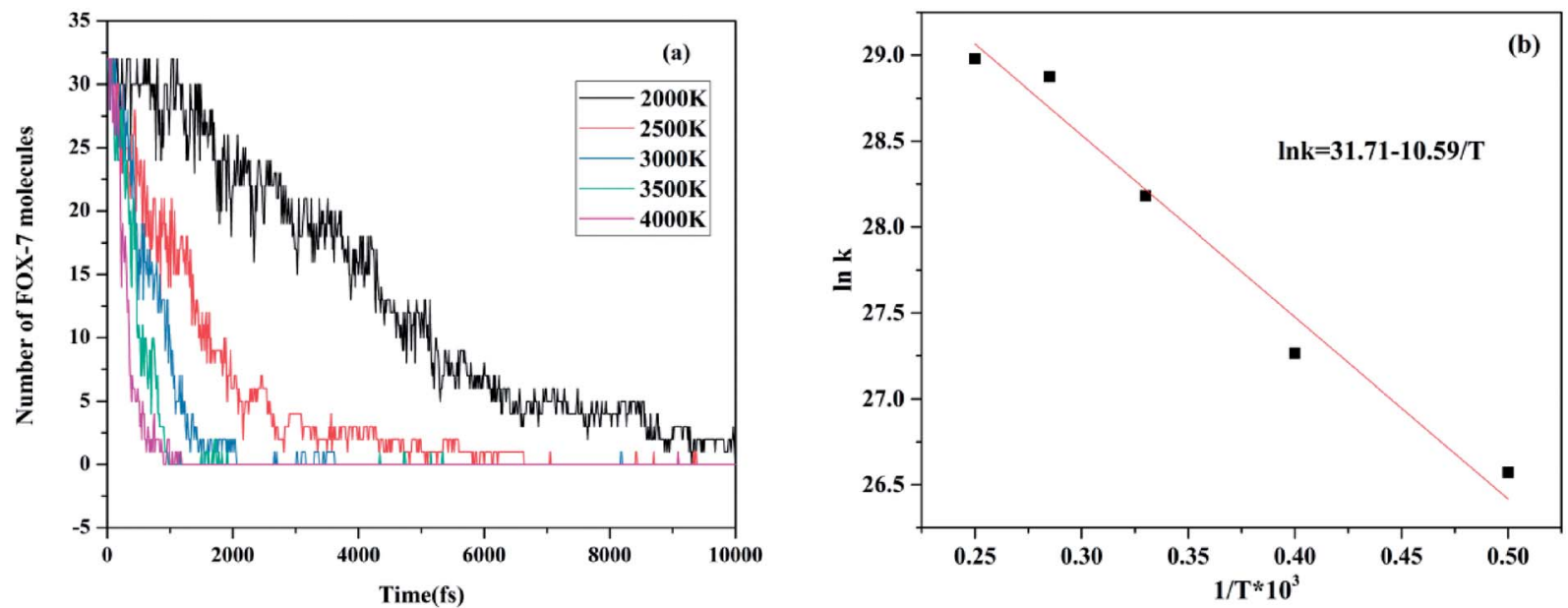

Fig. 11 (a) Evolution of pure FOX-7 molecules at various temperatures and (b) Arrhenius plot of the rate constants of pure FOX-7 molecules at various temperatures.

Table 3 Fitting-related parameters of the Arrhenius equation for FOX7 molecules

\begin{tabular}{llllll}
\hline$T / \mathrm{K}$ & $1 / T \times 10^{3}$ & $N_{0}$ & $t / \mathrm{ps}$ & $K \times 10^{12}$ & $\ln k$ \\
\hline 2000 & 0.5 & 32 & 10 & 0.3465 & 26.5711 \\
2500 & 0.4 & 32 & 5 & 0.6931 & 27.2644 \\
3000 & 0.33 & 32 & 2 & 1.7328 & 28.1807 \\
3500 & 0.285 & 32 & 1 & 3.4657 & 28.8739 \\
4000 & 0.25 & 32 & 0.9 & 3.8508 & 28.9793
\end{tabular}

step of 0.25 fs at $3000 \mathrm{~K}$ were performed for six FOX-7 molecules. Starting from these final product molecules, the formation pathways could be found by a reverse mapping strategy from the movie interface of the ADF software. The final decomposition products of FOX-7 are $\mathrm{N}_{2}, \mathrm{NH}_{3}, \mathrm{CO}_{2}, \mathrm{H}_{2} \mathrm{~N}_{2}, \mathrm{H}_{2} \mathrm{O}$, $\mathrm{HN}_{2}$, and $\mathrm{H}_{2}$. Table 2 presents the corresponding results.

We first focused on the formation of $\mathrm{CO}_{2}$ molecules. The $\mathrm{CO}$ molecules interact with each other to generate $\mathrm{CO}_{2}$ and $\mathrm{O}$. The gain and loss of an $\mathrm{O}$ atom occurs between $\mathrm{CO}_{2}$ and $\mathrm{CO}$. Another $\mathrm{CO}_{2}$ formation channel is the uptake of $\mathrm{O}$ atoms from $\mathrm{NO}_{2}$ or $\mathrm{NO}$ by $\mathrm{CO}$ to generate $\mathrm{CO}_{2}$ and other products. Water molecule formation occurs via a relatively complex process. The first pathway is the reaction of $\mathrm{NH}_{3}$ with $\mathrm{NO}$ to produce $\mathrm{H}_{2} \mathrm{~N}_{2}$ and $\mathrm{OH}$, which then decompose into $\mathrm{HN}_{2}$ and $\mathrm{H}_{2} \mathrm{O}$, respectively. The second pathway is the combination of $\mathrm{OH}$ and $\mathrm{NO}$ to generate HONO. Subsequently, HONO reacts with $\mathrm{H}$ to provide $\mathrm{H}_{2} \mathrm{O}$ and NO. The last route is the reaction of an $\mathrm{H}$ atom with $\mathrm{NO}_{2}$ to form $\mathrm{HNO}_{2}$, and then, $\mathrm{HNO}_{2}$ reacts with $\mathrm{HN}_{2}$ to produce $\mathrm{HNOOH}$ and $\mathrm{N}_{2}$. HNOOH eventually decomposes into $\mathrm{H}_{2} \mathrm{O}$ and NO. Nitrogen is mainly produced by the decomposition of $\mathrm{H}_{2} \mathrm{~N}_{2}$ and $\mathrm{HN}_{2}$. The $\mathrm{NH}_{3}$ molecules are usually generated from the reaction of $\mathrm{NH}_{2}$ with $\mathrm{H} . \mathrm{H}_{2} \mathrm{~N}_{2}$ is produced by three channels: $\mathrm{HN}_{2}$ can turn into $\mathrm{H}_{2} \mathrm{~N}_{2}$ by taking an $\mathrm{H}$ atom from $\mathrm{H}_{2} \mathrm{~N}_{2}$; two $\mathrm{NH}$ groups can also form $\mathrm{H}_{2} \mathrm{~N}_{2}$; and $\mathrm{H}_{2}$ can react with $\mathrm{N}_{2}$ to produce $\mathrm{H}_{2} \mathrm{~N}_{2} \cdot \mathrm{H}_{2}$ is mainly produced by the decomposition of $\mathrm{NH}_{3}$, $\mathrm{NH}_{4}$, and the intermediates $\mathrm{H}_{2} \mathrm{~N}_{2}$ and $\mathrm{H}_{3} \mathrm{~N}_{2}$. Another scheme is the reaction between $\mathrm{HN}_{2}$ and $\mathrm{NH}_{3}$. The formation of $\mathrm{HN}_{2}$ also occurs via several pathways. The first pathway is the decomposition of $\mathrm{H}_{2} \mathrm{~N}_{2}$. The addition of an $\mathrm{H}$ atom to $\mathrm{N}_{2}$ can generate $\mathrm{HN}_{2}$. The third route is the formation of $\mathrm{HNO}_{2}$ by an $\mathrm{H}$ atom and $\mathrm{NO}_{2}$, followed by the reaction of $\mathrm{HNO}_{2}$ with $\mathrm{N}_{2}$. The $\mathrm{H}$ atom is detached from $\mathrm{H}_{2} \mathrm{~N}_{2}$, and then, this detached $\mathrm{H}$ atom can react with $\mathrm{OH}$ to generate $\mathrm{H}_{2} \mathrm{O}$. The last channel is the transfer of an $\mathrm{H}$ atom from $\mathrm{NH}_{3}$ to $\mathrm{N}_{2}$ to generate $\mathrm{HN}_{2}$.

\subsection{Apparent kinetics of the initial reactions}

Understanding the initial reaction kinetics of energetic compounds is of great significance for the theoretical research and practical applications of these compounds. The 10 ps NVTMD simulations were performed at 2000, 2500, 3000, 3500, and $4000 \mathrm{~K}$ for FOX-7. The decomposition reaction can be fitted to the first-order reaction kinetics, as presented in eqn (4).

$$
-\mathrm{d}[\mathrm{FOX}-7] / \mathrm{d} t=k[\mathrm{FOX}-7]
$$

where [FOX-7] is the number of FOX-7 molecules, $k$ is the reaction rate constant, and $t$ is the time.

The eqn (4) can also be written as eqn (5):

$$
\ln \left[N_{0} / N_{t}\right]=k t
$$

where $N_{0}$ is the initial number of FOX-7 molecules.

The relationship between the reaction rate constant and temperature can be fitted to the Arrhenius eqn (6):

$$
k=A \exp \left(-E_{\mathrm{a}} / R T\right)
$$

where $A$ is the pre-exponential factor, $R$ is the molar gas constant $\left(8.314 \mathrm{~J} \mathrm{~mol}^{-1} \mathrm{~K}^{-1}\right)$, and $E_{\mathrm{a}}$ is the activation energy.

The evolution of the pure FOX-7 molecules at various temperatures is exhibited in Fig. 11. According to the data provided in Fig. 11a, Table 3 was created, which presents the relevant parameters of the fitted Arrhenius equation for FOX-7, where $T$ is temperature, $N_{0}$ is the initial number of FOX-7 
molecules, $t$ is time, and $k$ is the reaction rate constant. After this, using the relationship between $\ln k$ and $1 / T$, an Arrhenius plot of the rate constants of pure FOX-7 molecules at various temperatures was obtained. The intercept and slope obtained from Fig. $11 \mathrm{~b}$ are 31.71 and -10.59 , respectively, which indicate that $-E_{\mathrm{a}} / R$ is -10.59 and $\ln A$ is 31.71 . Consequently, the activation energy of the decomposition reaction for FOX-7 was calculated to be $88.04 \mathrm{~kJ} \mathrm{~mol}^{-1}$, and the pre-index factor was $5.90 \times 10^{13}$. However, the activation energy measured by differential scanning calorimetry was $58 \mathrm{kcal} \mathrm{mol}^{-1},{ }^{39}$ which is higher than the calculated activation energy.

\section{Conclusions}

Herein, the thermal decomposition behavior of FOX-7 was investigated by molecular dynamics simulations and online photoionization mass spectrometry (TG-PI-TOF-MS and SPITOF-MS). The evolution of the energy release and major products and formation mechanisms of the final products were further studied. The conclusions are as follows:

(1) The evolution of the major products of FOX-7 decomposition demonstrates that $\mathrm{N}_{2}, \mathrm{NH}_{3}, \mathrm{CO}_{2}$, and $\mathrm{H}_{2} \mathrm{~N}_{2}$ are the dominant products of thermal decomposition and $\mathrm{H}_{2} \mathrm{O}, \mathrm{HN}_{2}$, and $\mathrm{H}_{2}$ are the minor products.

(2) By combining the mass spectrometry data with the molecular dynamics simulation results, we proposed a decomposition pathway for $\mathrm{FOX}-7$ : $\mathrm{C}-\mathrm{NO}_{2}$ fission is the initial step responsible for the dissociation of $\mathrm{FOX}-7$, and then, the remaining structure undergoes a three-membered ring transition state to form $\mathrm{C}=\mathrm{O}$ followed by $\mathrm{C}-\mathrm{NO}$ cleavage and the loss of $\mathrm{NH}_{2}$ and $\mathrm{H}$; this results in the formation of the $\mathrm{NHC}=\mathrm{C}=\mathrm{O}$ structure, which finally breaks down into $\mathrm{HNC}$ and CO. $\mathrm{NH}_{2}$ can react with an $\mathrm{H}$ atom to produce $\mathrm{NH}_{3}$.

(3) The formation pathway of the final products was identified from the initial products and intermediate products by a reverse mapping strategy.

These findings are favorable for understanding the mechanisms of FOX-7 thermolysis. Moreover, the TG-PI-TOF-MS and SPITOF-MS techniques are effective experimental tools for decomposition mechanism studies and the identification of the products generated by the decomposition of energetic compounds.

\section{Conflicts of interest}

There are no conflicts to declare.

\section{Acknowledgements}

This work was supported by the National Natural Science Foundation of China (21975150) and China Postdoctoral Science Foundation (2019M653532).

\section{References}

1 K. Agamemnon, P. Julius, F. Jacqueline, S. David, S. Benjamin and B. Washington, J. Hazard. Mater., 2012, 219-220, 75-81.
2 N. N. Perreault, A. Halasz, S. Thiboutot, G. Ampleman and J. Hawari, Environ. Sci. Technol., 2013, 47, 5193-5198.

3 N. V. latypov, J. Bergman, A. Langlet, U. Wellmar and U. Bemm, Tetrahedron, 1998, 54, 11525.

4 U. Bemm and H. Ostmark, Acta Crystallogr., Sect. C: Cryst. Struct. Commun., 1998, 54, 1997-1999.

5 R. Gilardi, Crystallographic data (excluding structure factors) for the DADNE structure have been deposited with the Cambridge Crystallographic Data Centre, 12 Union Road, Cambridge CB2 1EZ, UK, 1999.

6 Q. Wu, W. H. Zhu and H. M. Xiao, J. Mol. Model., 2013, 19, 4039-4047.

7 W. A. Trzcinski, S. Cudzilo, Z. Chylek and L. Szymanczyk, J. Hazard. Mater., 2008, 157, 605-612.

8 B. Janzon, H. Bergman, C. Eldsaeter, C. Lamnevik and H. OestmarkInternational Symposium on Ballistics, Proceedings, 20th, Orlando, FL, United States, 2002, vol. 1, pp. 686-693.

9 W. P. C. de Klerk, C. Popescu and A. E. D. M. van der Heijden, J. Therm. Anal. Calorim., 2003, 72, 955-966.

10 A. Gindulyté, L. Massa, L. Huang and J. Karle, J. Phys. Chem. A, 1999, 103, 11045-11051.

11 A. V. Kimmel, P. V. Sushko, Â. L. Shluger and M. M. Kuklja, AIP Conf. Proc., 2007, 955, 389.

12 Z. Y. Zheng, J. C. Xu and J. J. Zhao, High Pressure Res., 2010, 30, 301-309.

13 D. E. Taylor, F. Rob, B. M. Rice, R. Podeszwac and K. Szalewicz, Phys. Chem. Chem. Phys., 2011, 13, 1662916636.

14 B. Yuan, Z. J. Yu and E. R. Bernstein, J. Chem. Phys., 2014, 140, 074708.

15 V. G. Kiselev and N. P. Gritsan, J. Phys. Chem. A, 2014, 118, 8002-8008.

16 Y. Liu, F. Li and H. Sun, Theor. Chem. Acc., 2014, 133, 1567. 17 R. S. Booth and L. J. Butler, J. Chem. Phys., 2014, 14, 134315.

18 H. Y. Jiang, Q. J. Jiao and C. Y. Zhang, J. Phys. Chem. C, 2018, 122, 15125-15132.

19 D. Xiang and W. H. Zhu, Can. J. Chem., 2019, 97, 795-804.

20 A. Strachan, A. C. T. van Duin, D. Chakraborty, S. Dasgupta and W. A. Goddard, Phys. Rev. Lett., 2003, 91, 098301.

21 K. I. Nomura, R. K. Kalia, A. Nakano and P. Vashishta, Phys. Rev. Lett., 2007, 99, 148303.

22 K. Zheng, Y. S. Yu, B. Huang, J. Wang, J. Chen, G. N. Xie, G. Q. Lv, J. Liu, Z. Q. Qiao and G. C. Yang, Phys. Chem. Chem. Phys., 2019, 21, 17240-17252.

23 M. A. Wood, A. C. T. van Duin and A. Strachan, J. Phys. Chem. $A, 2014,118,885-895$.

24 X. N. Huang, Z. Q. Qiao, X. G. Dai, K. L. Zhang, M. Li, G. Pei and Y. S. Wen, J. Appl. Phys., 2019, 125, 195101.

25 T. T. Zhou, H. J. Song, Y. Liu and F. L. Huang, Phys. Chem. Chem. Phys., 2014, 16, 13914-13931.

26 A. C. T. van Duin, Y. Zeiri, F. Dubnikova, K. Ronnie and W. A. Goddard, J. Am. Chem. Soc., 2005, 127, 11053-11062.

27 T. R. Shan, R. R. Wixom and A. P. Thompson, Phys. Rev. B, 2016, 94, 054308. 
28 D. Furman, R. Kosloff, F. Dubnikova, S. V. Zybin, W. A. Goddard, N. Rom, B. Hirshberg and Y. Zeiri, J. Am. Chem. Soc., 2014, 136, 4192-4200.

29 Q. L. Yan, S. Zeman, P. E. Sánchez Jiménez, T. L. Zhang, L. A. Pérez-Maqueda and A. Elbeih, J. Phys. Chem. C, 2014, 118, 22881-22895.

30 F. P. Wang, L. Chen, D. S. Geng, J. Y. Wu, J. Y. Lu and C. Wang, J. Phys. Chem. A, 2018, 122, 3971-3979.

31 J. C. Xu, Y. C Bian, Y. Liu and D. Zhai, Comput. Mater. Sci., 2017, 131, 126-131.

32 C. M. Zhang, X. L. Fu, Q. L. Yan, J. Z. Li, X. Z. Fan and G. F. Zhang, RSC Adv., 2019, 9, 33268-33281.

33 J. J. Weng, Y. X. Liu, Y. N. Zhu, Y. Pan and Z. Y. Tian, Bioresour. Technol., 2017, 244, 125-131.
34 Y. Wang, Y. N. Zhu, Z. Y. Zhou, J. Z. Yang, Y. Pan and F. Qi, Energy Fuels, 2016, 30, 1534-1543.

35 Z. Y. Zhou, C. J. Liu, X. M. Chen, H. Ma, C. C. Zhou, Y. Z. Wang and F. Qi, J. Anal. Appl. Pyrolysis, 2019, 137, 285-292.

36 Y. Wang, Q. Huang, Z. Y. Zhou, J. Z. Yang, F. Qi and Y. Pan, Energy Fuels, 2015, 29, 1090-1098.

37 Z. X. Zhu, J. Wang, K. Q. Qiu, C. Y. Liu, F. Qi and Y. Pan, Rev. Sci. Instrum., 2014, 85, 046110.

38 F. P. Wang, L. Chen, D. S. Geng, J. Y. Wu, J. Y. Lu and C. Wang, J. Phys. Chem. A, 2018, 122, 3971-3979.

39 O. Henric, B. Helena, B. Ulf, G. Patrick, H. Erik, J. Martin, L. Abraham, L. V. Nikolaj, P. Anna, P. Marja-Liisa, W. Niklas, V. Carin, S. Helen, K. Lars and H. Maija, Int. Annu. Conf. ICT, 2001, 32, 26. 